\title{
Assessment and Analysis of Sustainability of the Socio- Economic Development of Amalgamated Territorial Communities of the Region
}

\author{
By Roman Khirivskyi ${ }^{1}$, Heorhii Cherevko ${ }^{1}$, Ihor Yatsiv $^{1}$, Tymofii Pasichnyk ${ }^{2}$, \\ Liudmyla Petryshyn ${ }^{1}$, Lesia Kucher ${ }^{3}$
}

\begin{abstract}
The article supplies assessment and analysis of sustainability of the socio-economic development of amalgamated territorial communities in Lviv region of Ukraine basing on the methodological approach, proposed by the authors and founded on the principal functions, performed by the territorial communities, and on the estimates of the degree of their fulfilment. Those methods suggest use of a set of indices, which express sustainable or unsustainable development of the economic indices and consider their different intention. Referring to the indices of execution of the local budgets of 22 communities in Lviv region, the authors of the research assess the socioeconomic situation of amalgamated territorial communities. Results of the calculations confirm the sufficient sustainability of the socio-economic development of amalgamated territorial communities in Lviv region. However, in 2018, the communities had trouble in executing their socio-economic budgets. The best results of development of the socio-economic indices were demonstrated by Babyna ATC, Davydiv ATC and Zabolottsi ATC, the worse ones - by Biskovychi ATC, Hrabovets ATC and Novyi Kalyniv ATC. To raise the level of the socio-economic standards of living of the "low-performing" amalgamated territorial communities and to support their sustainable development, the government should supply its assistance.
\end{abstract}

Keywords: sustainability, socio-economic development, amalgamated territorial communities, Lviv region, Ukraine

\section{Introduction}

Sustainable development of a socio-economic system is one of the global problems of humanity. Currently, the theory of sustainable development of the socioeconomic system is at the stage of its establishment. There are still many unsolved and disputable issues. In particular, there are different ideas on the concept of socioeconomic development of the regional systems in total and territorial communities particularly. The most common idea is that the development should be sustainable [8].

The improvement of the methodological fundamentals and methods of analysis of the conditions and sustainability of development of the regional systems is a mandatory condition to raise the quality of managerial decisions basing on a more relevant analysis, forecast and adequate argumentation of the strategic directions of development of the economic complex, social and ecological spheres of the territories. Different authors propose different methodological fundamentals and methods to assess the degree of sustainability of development of the regional socio-economic systems of a different level. 
Foreign and domestic economists supply different interpretations of the concept of sustainable development of the territory. In particular, ambiguousness of those interpretations is stressed by V. Rokhchiv. He distinguishes three directions of the research on the essence of that concept:

1) as the sustainable development is interpreted as the economic growth, which secures satisfaction of material and cultural needs of the present and future generations while maintaining the ecosystem balance;

2) as the sustainable socio-economic development, which does not make harm to the natural basis of the territory;

3) as a permanent improvement of the living standards of population [16].

For instance, M. Khvesyk defines sustainable development as an extension of the concept of complex development of a region, which is based on the approach of reproduction.

Sustainable development suggests a transition to managing of the total integrity of economic, social, and natural processes occurring on the territory, as well as to the agreed decisions concerning location of production objects and population, whereas the economic system of sustainable development is based on the "reproductive economy» [9].

The definitions of sustainable development, expressed in its separate constituents but not revealing its complete idea, are described in the works by M. Babych [1], V. Chemerys, V. Dushka, V. Maksym and D. Solomonko [2], B. Danylyshyn, L. Shostak [3, p. 10], O. Kononenko [10], L. Korneichuk [11], I. Kravchuk, A. Rakovich [12], O. Pchelintsev [14, p. 34], T. Shovhenov [17], M. Zghurovskyi [21, p. 43-56].

Thus, there are different approaches to assessment of sustainability of the territory development [19]. V. Kretinin investigates the economic sustainability of the region, specifying innovative and investment activities, financial stability, economic efficiency, ecological stability, and reproductive integrity as its main components. The reproductive integrity is considered not only as a component of economic sustainability of the regional economic system, but also as a factor, influencing its other components, particularly ecological stability, investment activity and economic efficiency [13].

O. O. Yevsieieva describes sustainability as a crisis-free (or safe) development of the territory, and proposes a complex of safety indicators and standards of sustainable development, which concern the main forms of the territory safety, i.e. economic, social, ecological, as the fundamentals of the strategic analysis of the territory sustainable development [20].

The necessity to develop an integral index of sustainability of the development of a territorial unit and an algorithm of its calculation is argued by O. Prokopenko, L. Zharova, Ye. Sadchenko. They consider that such index will identify the most significant characteristics of the territory, determine the dynamics of the territory sustainable development, and compare one territory with the others in terms of sustainability of their development [15, p. 64-66].

A. Tatarkin et al. stresses on the necessity to develop quantitative and qualitative indices of economic stability of the region, to determine their range and optimal relations between them [18, p. 28-30].

Most researchers propose using the methods of economic-mathematic modeling of the 
processes of socio-economic stabilization and sustainable development of the regions, as well as multi-objective optimization of the ensured decisions of the primary problems, as instruments for investigation of the directions and development of the multi-objective programs of sustainable development of the region. They consider the principal goal of the optimization is to minimize financial costs while improving the relevance and accuracy of those decisions.

Currently, rating and rank characteristics, based on the procedures of integration of the indices of ecological and socio-economic development, are the most often used methods for assessment of the sustainability of the regional development in total and amalgamated territorial communities particularly.

The analysis of the existing methods for assessment of the sustainability of the regional development demonstrates that along with a high degree of relevance, most of them expect a complicated procedure of calculations, making use of them in the common practice rather confusing.

\section{Materials and Methods}

The goal of the article is to assess and analyze sustainability of the socioeconomic development of amalgamated territorial communities in Lviv region.

The work proposes a methodological approach to the analysis of conditions and sustainability of development of the socio-economic systems of amalgamated territorial communities, based on consideration of the principle functions, performed by the territorial communities and on the estimates of their fulfillment. The proposed methods of calculation of the factors of sustainable development of amalgamated territorial communities are based on close relations of the system of indices, which express sustainable or unsustainable development of the economic indices and consider their different intention.

\section{Results}

A complex of external and internal functions is the most important and essential characteristics of a territorial community as a socio-economic system. Those functions contribute to achieving the main goals of the region development, particularly performance of the role of amalgamated territorial communities in the socio-economic development of the country, creation of favorable life conditions, and improvement of the living standards of population, settled on the territories, as well as security of its selfprotection and self-development. In economic literature, those functions include the functions of demand and supply, functions of activity of the territorial objects, specialization of the region and regional management, economic, demographic, ecological an socio-household functions [7, p. 15-17].

The function of community management is one of the most common functions, performed by the amalgamated territorial community as a socio-economic system. It expects creation of the conditions for its self-protection and self-development on the base of the rational use of natural, productive, scientific, labor, demographic, social and cultural potential of the territory and improvement of its business activities. Performance 
of that function secures achievement of internal and external goals of the territorial development, particularly essential maintenance of life and raise of the standards of people's living, increase of the role of community in the social distribution of labor on the base of formation of the rational economic specialization.

That general function is fulfilled through the partial functions, which include the following ones:

- the economic function, which aims to satisfy the needs of the population of a definite territorial community for the essential goods and services;

- the financial function, which suggests supporting the financial stability and formation of the financial sources for self-development of the amalgamated territorial community (increase of the level of its budget self-sufficiency);

- the demographic function, which secures creating the appropriate conditions for protection and extended reproduction of population and labor potential on the community territory;

- the social function, which is fulfilled by creating the appropriate conditions for satisfaction of the socio-household and socio-cultural needs of population, improvement of the level and standards of living, protection of cultural and national traditions, and support of the socio-political stability on the amalgamated community territory;

- the environmental function, which is focused on creation of the economic and institutional conditions for protection and improvement of the environmental conditions, greening of production and improvement of the standards of people's life.

The different concepts on development of the regions and communities stress on some of those functions of the regional system development. In fact, those functions are interrelated. The fulfilment of one of them provides the appropriate conditions for the others. However, that process of impact of one function on the others can be contradictory. The most important characteristics of the conditions of an amalgamated territorial community is expressed by the socio-economic and ecological well-being of the territory of its performance. The definition of that notion is of great importance for development of the methodological fundamentals for assessment of the conditions and sustainability of the community development. The socio-economic and ecological wellbeing of an amalgamated territorial community manifests the degree of fulfilment of the principal functions of the regional system, which secure achievement of external and internal goals of the territory development. Sustainable development of the community demonstrates the dynamics of the territory socio-economic and ecological well-being, characterizing the capability of the regional socio-economic systems to a complete and balanced performance of the main functions during a long period to maintain its integrity and create conditions for its gradual development.

The proposed methodology is based on systematization and consolidation of the experience of practical application of the existing methodic approaches to assessment of the socio-economic situation on the territories of the regions of different levels, and it expects some stages.

1. First, to determine a list of initial indices and choose the most significant ones basing on their qualitative and quantitative analysis.

2. Second, to make calculations of some consolidated and integrated indices, as well as dynamic estimates of the socio-economic and ecological well-being of the amalgamated 
territorial community in the analyzed time interval.

3. Third, to develop the reference socio-economic subsystems on the studied region territory, e.g. on the base of artificial neuron nets.

4. Fourth, to assess the conditions and sustainability of development of the amalgamated territorial communities on the base of analysis of the composed indices of the socioeconomic and ecological well-being, dynamic integral estimates and typologies of the socio-economic subsystems, performing on the studied territory, by the years of the analyzed period.

5. Basing on the conducted analysis, to define the main problems and argue the priority directions of the sustainable socio-economic development of the amalgamated territorial communities.

The work supplies a detailed characteristic of the financial situation, which secures financial stability of the amalgamated territorial communities in Lviv region. To assess the socio-economic situation of the amalgamated territorial communities, the researchers have chosen some indices of execution of the local budgets of 22 communities in Lviv region referring to the reports on the financial (budget) activities of the amalgamated communities in 2016-2019 [4; 5; 6].

The relative standard $i$ index of execution of the socio-economic budgets of $j$ amalgamated territorial community is calculated by the formula:

$B_{i j}^{D}=\frac{B_{i j}-B_{i}^{\min }}{B_{i}^{\max }-B_{i}^{\min }}$,

where $B_{i j}-$ is the $i$ index of execution of the socio-economic budgets of $j$ amalgamated territorial community; $B_{i}^{\min }, B_{i}^{\max }$ - are the smallest and highest values of the $i$ index by all amalgamated territorial communities;

The consolidated index of execution of the socio-economic budgets is calculated by the formula:

$P_{j}=\frac{\sum_{i=1}^{n} B_{i j}^{D}}{n}$,

where $n-$ is the number of indices, chosen for assessment of the degree of fulfilment of one of the functions of activities of $j$ amalgamated territorial community.

The Table 1 presents calculated indices of execution of the socio-economic budgets of 22 amalgamated territorial communities of Lviv region in 2019. In the calculation algorithms, demonstrated in the Table, the authors of the research used the method of norming, applied while calculating the indices, included in the index of human potential development by the UNO methods, as well as in some other methodologies of comparative assessment of the socio-economic development of regions.

The value of the index equal to " 1 " means that the community performs the function of its financial solvency at the best level $(100 \%)$ as compared to other amalgamated territorial communities.

The Table 1 demonstrates that in 2019, the best indices of execution of the socioeconomic budgets were demonstrated by Davydiv ATC, with its consolidated index of 0.57. It means that Davydiv ATC implemented the financial levers at almost $57 \%$. The 
greatest problems of the socio-economic development were faced by Mostyska ATC, as compared to other amalgamated territorial communities in Lviv region.

The similar investigations were conducted in 2016-2018, which provided the following results. In 2016 and 2017, the best execution of the socio-economic budgets was reached by Vilshanyk ATC, where the consolidated index was equal to 0.7 , whereas the least value of the consolidated index (0.26 in 2016 and 0.25 in 2017) was shown by Khodoriv ATC. In 2018, the maximal value of the consolidated index (0.33) was secured by Davydiv ATC, whereas the least (0.08) - by Mostyska ATC. Those calculations showed insignificant discrepancy with the assessment of the results of monitoring of the local budgets execution $[4 ; 5 ; 6]$.

Table 1: Calculated indices of execution of the socio-economic budgets of amalgamated territorial communities of Lviv region in 2019

\begin{tabular}{|c|c|c|c|c|c|c|c|}
\hline No. & Title of ATC & 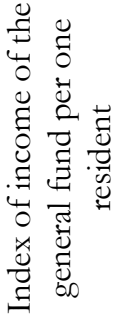 & 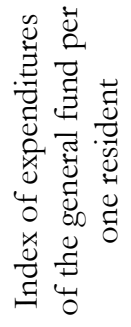 & 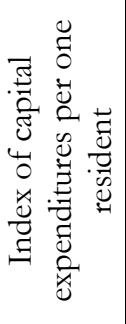 & 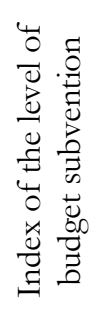 & 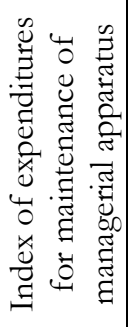 & 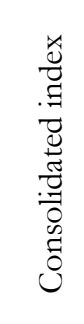 \\
\hline 1 & Babyna & 0.373 & 0.877 & 0.050 & 0.445 & 0.610 & 0.471 \\
\hline 2 & Biskovychi & 0.172 & 0.216 & 0.252 & 0.532 & 0.354 & 0.305 \\
\hline 3 & Vilshanyk & 0.027 & 0.355 & 0.085 & 0.901 & 0.925 & 0.458 \\
\hline 4 & Volia Baranetska & 0.016 & 0.124 & 0.082 & 0.938 & 1.000 & 0.432 \\
\hline 5 & Hnizdychiv & 0.406 & 0.326 & 0.030 & 0.239 & 0.026 & 0.206 \\
\hline 6 & Hrabovets & 0.251 & 0.133 & 0.054 & 0.498 & 0.526 & 0.292 \\
\hline 7 & Davydiv & 1.000 & 0.679 & 1.000 & 0.147 & 0.044 & 0.574 \\
\hline 8 & Dubliany & 0.240 & 0.224 & 0.429 & 0.486 & 0.289 & 0.334 \\
\hline 9 & Zhovtantsi & 0.580 & 0.599 & 0.115 & 0.005 & 0.000 & 0.260 \\
\hline 10 & Zabolottsi & 0.714 & 1.000 & 0.066 & 0.167 & 0.093 & 0.408 \\
\hline 11 & Luky & 0.025 & 0.161 & 0.039 & 0.913 & 0.664 & 0.360 \\
\hline 12 & Mizhenets & 0.041 & 0.078 & 0.102 & 0.840 & 0.985 & 0.409 \\
\hline 13 & Mostyska & 0.354 & 0.346 & 0.039 & 0.193 & 0.000 & 0.187 \\
\hline 14 & Nyzhankovychi & 0.201 & 0.325 & 0.711 & 0.449 & 0.386 & 0.414 \\
\hline 15 & Novyi Kalyniv & 0.570 & 0.321 & 0.059 & 0.000 & 0.206 & 0.231 \\
\hline 16 & Nove Misto & 0.000 & 0.000 & 0.067 & 1.000 & 0.601 & 0.334 \\
\hline 17 & Novi Strilyshcha & 0.271 & 0.439 & 0.000 & 0.472 & 0.336 & 0.304 \\
\hline 18 & Sudova Vyshnia & 0.228 & 0.477 & 0.146 & 0.528 & 0.209 & 0.318 \\
\hline 19 & Trostianets & 0.647 & 0.659 & 0.077 & 0.206 & 0.095 & 0.337 \\
\hline 20 & Khodoriv & 0.345 & 0.485 & 0.061 & 0.344 & 0.015 & 0.250 \\
\hline 21 & Chukva & 0.123 & 0.414 & 0.080 & 0.654 & 0.580 & 0.370 \\
\hline 22 & Shehyni & 0.733 & 0.737 & 0.126 & 0.103 & 0.107 & 0.361 \\
\hline
\end{tabular}

Source: composed by the authors basing on the results of monitoring of the local budgets execution [4] and formulas (1), (2). 
The Fig. 1 presents the consolidated indices of execution of the socio-economic budgets of amalgamated territorial communities in Lviv region in 2016-2019. The figures at the diagram stand for the titles of the ATCs referring to the Table 1.

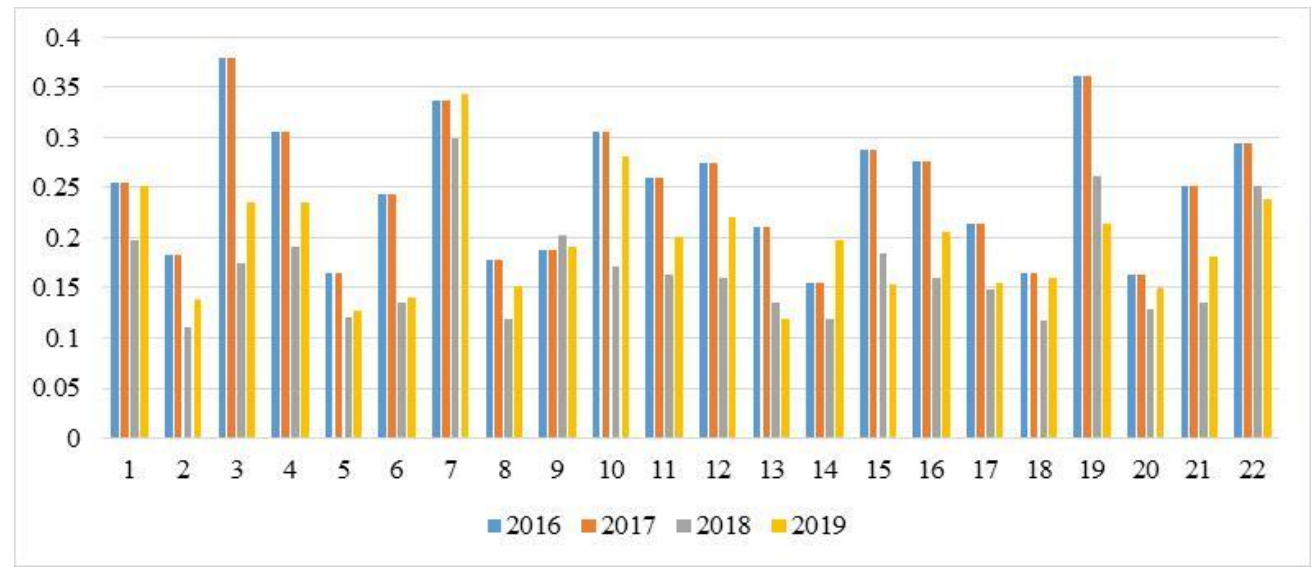

Figure 1: The consolidated indices of amalgamated territorial communities in Lviv region in 2016-2019 Source: built by the authors.

The total consolidated index of execution of the socio-economic budgets of amalgamated territorial communities is calculated by the formula:

$P=\frac{\sum_{j=1}^{k} P_{j}}{k}$,

Having done the appropriate calculations, the researchers obtain the following results (Fig. 2).

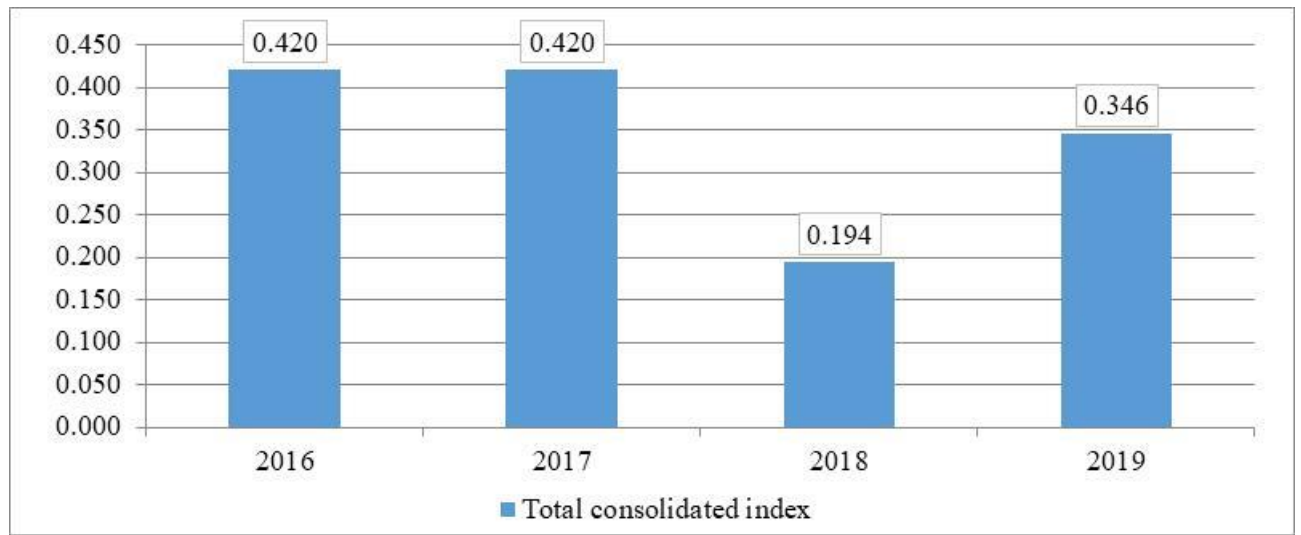

Figure 2: The total consolidated index of execution of the socio-economic budgets of amalgamated territorial communities of Lviv region in 2016-2019

Source: built by the authors. 
Referring the data of the Table 2, one can conclude that 2018 was a difficult year for amalgamated territorial communities of Lviv region in terms of execution of their socioeconomic budgets.

To assess the dynamics of the level of socio-economic development of ATCs, the mentioned methodology involves modification of the models of static and dynamic integral estimates, which have been developed for determination of the advantages of the potential objects (enterprises) for investing and can be also used for estimation of sustainability of the socio-economic development of amalgamated territorial communities. They are calculated by the following formulas.

The integral index of the socio-economic development of amalgamated territorial communities is calculated by the formula:

$P_{j t}=\sqrt{\sum_{i=1}^{n} \gamma_{i}^{2} B_{i j t}^{2}}$,

where $B_{i j t}$ - is the $i$ index of execution of the socio-economic budgets of $j$ amalgamated territorial community in $t$ year; $\gamma-$ is a weight factor (relative significance of each of the studied indices).

The static integral estimates of sustainability of the socio-economic development of amalgamated territorial communities are calculated by:

$$
R_{j t / t-1}=\frac{2 P_{j t}^{2}}{P_{j t}^{2}+P_{j t-1}^{2}-\bar{P}_{j t}^{2}},
$$

where $\bar{P}_{j t}$ - is the dynamic integral estimation of the socio-economic development of ATC, which is calculated by the formula:

$$
\bar{P}_{j t}=\sqrt{\sum_{i=1}^{n} \gamma_{i}^{2}\left(B_{i j t}-B_{i j t-1}\right)^{2}} \text {. }
$$

The values of the dynamic integral estimates of sustainability of the socio-economic development of amalgamated territorial communities in Lviv region are demonstrated at the Fig. 3.

The Fig. 3 shows that for the last three years, the best figures of sustainable development of the socio-economic indices have been achieved by Babyna ATC, Davydiv ATC, Zabolottsi ATC, and on the contrary, the worst figures of sustainable development of the socio-economic indices have been demonstrated by Biskovychi ATC, Hrabovets ATC and Novyi Kalyniv ATC.

To raise the level of the socio-economic standards of living of the "low-performing" amalgamated territorial communities and to support their sustainable development, the government should supply its assistance. The state regulation of the investment process at the regional level, as well as stimulation of development of small business and integration relations between communities are some of the forms of such support. 


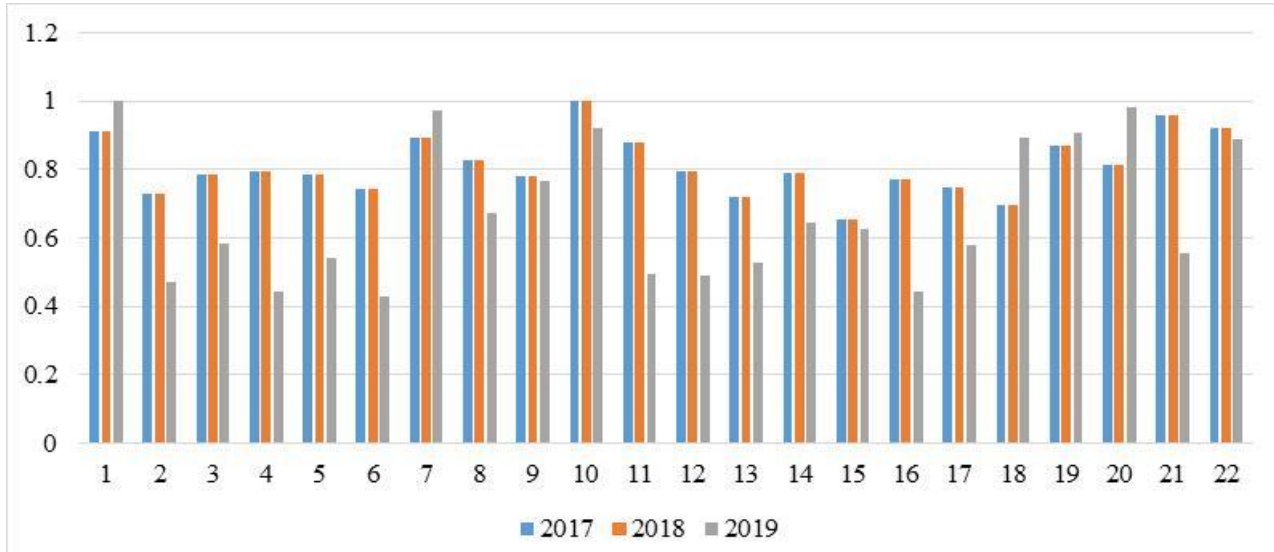

Figure 3: The static integral estimates of sustainability of the development of amalgamated territorial communities of Lviv region in 2017-2019

Source: built by the authors.

A similar method is used to measure economic, demographic, social and environmental functions for maximal satisfaction of people's needs for necessary goods and services, protection and extension of labor potential on the community territory, creation of the appropriate conditions for satisfaction of socio-economic and socio-cultural needs of population, use of the ecological potential of amalgamated territorial communities.

\section{Conclusions}

The performed calculations demonstrate the sufficient socio-economic development of amalgamated territorial communities in Lviv region. The majority of amalgamated territorial communities have reached the level of development equal to $60 \%$.

The consolidated and integral indices can be used for comparative assessment of the socio-economic development of amalgamated territorial communities by means of ranging the last ones, as well as for determination of the appropriate tools for fulfilment of the functions of socio-economic subsystems in the region. To get the relative estimates of the actual conditions of each subsystem, it is necessary to compare it with the ideal conditions or conditions of the "reference subsystem". The proposed methods are universal. They can be used to analyze development of any region. Considering the correction of the set initial indices, the methodology can be also used for a comparative analysis of the conditions and sustainability of development of the subjects, located on large territories, i.e. the country in total. The analysis results can be used while developing monitoring, scenarios and strategies of the socio-economic development of the objects of different levels. 


\section{References}

Babych, M. (2018). Social-economic and environmental sustainability of short supply chains: opportunities for development rural territories. Agricultural and Resource Economics, 4(1): 42-59. Available at: http://are-journal.com.

Chemerys, V., Dushka, V., Maksym, V. and Solomonko, D. (2019). Business-model of rural areas development in Ukraine. Agricultural and Resource Economics, 5(1): 154-176. Available at: http://arejournal.com.

Danylyshyn, B. and Shostak, L. B. (1999). Sustainable development in the system of natural-resource restrictions. Kyiv: SOPS Ukraine NASU. 367 p.

Estimation of the financial indices of the budgets of 806 ATC. Rating in 2019. Available at: https://decentralization.gov.ua/news/12192.

Estimation of the financial solvency of 366 ATC in 2017 in terms of regions. Available at: https://www.kmu.gov.ua/storage/app/media/reforms/53-rezultati-finansovogo-monitoringu366-otg-za-1pivrichchya-2017-roku-stvorenikh-u-2015-ta-2016-rokakh.pdf.

Experts analyzed budgets of amalgamated communities of each region in 2018. Available at: https://decentralization.gov.ua/news/10674.

Hutman, H. V., Miroiedov, A. A. and Fedin, S. V. (2002). Management of regional economy. Moscow: Finance and statistics. $176 \mathrm{p}$.

Ihnatieva, E. D. and Mariev, O. S. (2008). Methodological fundamentals of the analysis of sustainability of development of the regional socio-economic systems. Journal of USTU-UPI. Series Economics and Management, 5: 56-66.

Khvesyk, M. A. and Khvesyk, Yu. M. (2013). Sustainable development of a territory as a fundamental of the strategy of agrarian sector development. Ekonomica APK, 1: 66-76.

Kononenko, O. (2019). Transformation of land relations regulation mechanism throughout the rural sustainable development context. Agricultural and Resource Economics, 5(1): 19-36. Available at: http://are-journal.com.

Korneichuk, L. (2008). Economic growth and sustainable development. Economy of Ukraine, 4: 82-90.

Kravchuk, I. and Rakovich, A. (2018). Entrepreneurial potential of rural territories as an object of scientific research. Agricultural and Resource Economics, 4(2): 69-84. Available at: http://are-journal.com.

Kretinin, V. A. (2015). Main components and indices of economic sustainability of the economic system of a region. Available at: http://www.amr.vladimir.ru/text/kret3.htm.

Pchelintsev, O. (2004). Regional economy in the system of sustainable development. Institute of National Economic forecasting of RAS. Moscow: Nauka. 258 p.

Prokopenko, O. V. ed. (2014). Sustainable development of an enterprise, region, society: innovative approaches to the supply: monograph. Poland: «Drukarnia i Studio Graficzne Omnidium». 474 p.

Rokhchin, V.E. (2005). Issues of the methodology of shaping of the system of strategic planning of development of the cities in Russia. Space Economy, 1: 103-116.

Shovhenov, T. M. (2007). Principal aspects of sustainability of the regional socio-economic systems. Regional economy and management, 3(11): 1107.

Tatarkin, A. I., Lvov, D. S., Myzin, A. L. et al. (1999). Modeling of sustainable development as a condition of improvement of the economic safety of a territory. Ekaterinburg: Published by Ural University. $276 \mathrm{p}$.

Yatsiv, I., Khirivskyi, R., Pasichnyk, T., Petryshyn, L. and Kucher, L. (2019). Assessment of the efficiency of resource potential employment by the communities of Lviv region of Ukraine. European Journal of Sustainable Developmen, 8(2): 165-176. https://doi.org/10.14207/ejsd.2019.v8n2p165.

Yevsieieva, O. O. (2005). Improved stability and adaptability of the region development. Economic space, 101: $72-81$.

Zghurovskyi, M. (2006). Sustainable development in global and regional terms: analysis according to the data of 2005. Kyiv: NTUU “KPI”. 84 p. 